\title{
Effect of Biological Solution and $p H$ on Corrosion Resistance of 304L SS for Dental Brackets
}

\section{LIDIA BENEA, NICOLETA SIMIONESCU*}

Research (Competences) Centre: Interfaces-Tribocorrosion-Electrochemical Systems (CC-ITES), Dunarea de Jos University of Galati, 47 Domneasca Str., 800008 Galati, Romania

Abstract. This study is undertaken to evaluate the accuracy of corrosion resistance of commercially available $304 \mathrm{~L}$ stainless steel in biological solutions with different composition and $\mathrm{pH}$. Electrochemical methods such as: open circuit potential (OCP), potentiodynamic polarization curves $(P D)$, linear polarization resistance $(R p)$ and cyclic polarization $(C V)$ were used for corrosion investigations. The results show different behavior during corrosion tests in the solutions with different $\mathrm{pH}$, different content of chlorides and different oxidizing character. Highest instability is revealed for $304 L$ stainless steel in Hank's solution due to the presence of chloride aggressive ions.

Keywords: 304L stainless steel, biological solutions, corrosion resistance, electrochemical methods.

\section{Introduction}

In addition to many industrial applications and food industry, 304L stainless steel is also used in some implants (tooth straightening system, screws, ceramic teeth resistance structure, orthodontic brackets etc.) [1,2]. Even if 304L stainless steel is a material with high corrosion resistance, however, it can be corroded in the oral cavity or human body while under conditions of low $\mathrm{pH}$, the presence of dental plaque, and a high chloride ion concentration [3]. The $p \mathrm{H}$ of the biological environment in which orthodontic systems are used has a significant effect on the rate of corrosion. When the orthodontic systems are combined with a ligature wire or an elastomeric O-ring, crevice and galvanic corrosion can occur in the oral cavity, and further types of corrosion may develop. Pitting corrosion of orthodontic appliances is common due to the aggressive action of chloride ions in saliva, or from food and drinks [1,4]. Although chloride ions etching is probably the major cause of corrosion, bacteria and their waste or metabolic products, may all contribute to the corrosion of orthodontic systems in the mouth. The large population of bacteria and fungi present in the oral cavity may accelerate the corrosion of 304L stainless steel orthodontic appliances. Organic acids and enzymes in particular may affect various orthodontic appliances [5,6].

The corrosion resistance of the biocompatible alloys used in implants is of particular importance not only because of the increased life of the implanted device but also because the corrosion process has harmful effects on the body [1,7]. The biological fluid in the human body contains water, salt, dissolved oxygen, bacteria, proteins, and a variety of ions, chlorides and hydroxides, so the human body is therefore a very aggressive environment for metals and in conclusion the products resulting from the corrosion process affect metabolism and cellular behavior $[8,9]$.

In recent decades, corrosion of orthodontic brackets in different spices has been investigated [10] showing that turmeric and coriander are effective in reducing corrosion. The effect of fruit juices and chloride ions on the corrosion behavior of orthodontic archwire [11] was investigated by $\mathrm{M}$. Sharma et al. The corrosion of stainless steels in artificial saliva with different fluoride contents [12] was investigated by M. Fan et al. The effect of dietary spices on the pitting behavior of stainless steel orthodontic bands [13] was investigated by N. Mahato et al, showing that coriander acts as an effective inhibitor. The correlation between surface physicochemical properties and the release of iron from stainless steel AISI 304 in biological media [14] was investigated by Y Hedberg et al.

*email: Lidia.Benea@ugal.ro 
This study was making to evaluate the accuracy of corrosion resistance of commercially available 304L stainless steel in biological solutions with different composition and $p \mathrm{H}$. Thus, two solutions simulating human body fluids (SBFs) such as Hank's solution having a $p \mathrm{H}$ of 7.25 and Fusayama Mayer saliva having a $p \mathrm{H}$ of 4.8 were chosen. The two solutions also have different concentrations of chlorides. Citric acid was chosen as a test solution being an organic compound very used in the food industry. The results showed the effects of chloride content and also the solution $p \mathrm{H}$ on the corrosion behavior of 304L stainless steel.

\section{Materials and methods}

\section{Electrochemical cell and solution composition}

Electrochemical tests were performed on 304L stainless steel biomaterial alloy intended for dentistry. The samples with active area of $3.5 \mathrm{~cm}^{2}$ were connected with a copper wire and after were polished successively with waterproof abrasive paper with grain size from 320-4000 mesh, with diamond paste of dimensions 3-1 $\mu \mathrm{m}$ and a suspension of $\mathrm{SiO}_{2}$ (particle size $0.04 \mu \mathrm{m}$ ) to achieve a mirror surface. Polished samples were cleaned with ethanol and dried after with hot air and stored in desiccators. A three electrode cell was used and consists of: as working electrode (WE) the $304 \mathrm{~L}$ stainless steel sample with active area of $3.5 \mathrm{~cm}^{2}$, an $\mathrm{Ag} / \mathrm{AgCl}$ (saturated solution of $\mathrm{KCl}$ ) as reference electrode (RE) and a Pt-Rh grid as the counter electrode (CE). Two types of simulated body fluids were selected, namely Hank's solution $(p \mathrm{H}=7.25)$ and Fusayama Meyer artificial saliva $(\mathrm{pH}=4.8)$ [15], Citric acid $p \mathrm{H}=1.81$ ) was also selected for corrosion study of 304L stainless steel because it is found in citrus juice, apples, tobacco leaf, wine, etc. and can affect the composition and change the $\mathrm{pH}$ of the mouth cavity. The solution composition is shown in Table 1. All solutions were prepared with distilled water and chemical analytical purity compounds.

Tabel 1. The chemical composition of solutions used

\begin{tabular}{|c|c|c|c|c|}
\hline Nr. Crt. & Compound & $\begin{array}{c}\text { Solution } \\
\text { Hank }\end{array}$ & $\begin{array}{c}\text { Saliva Fusayama } \\
\text { Meyer (SFM) }\end{array}$ & Acid citric \\
\hline 1. & $\mathrm{NaCl}$ & $8 \mathrm{~g} / \mathrm{L}$ & $0.4 \mathrm{~g} / \mathrm{L}$ & - \\
2. & $\mathrm{KCl}$ & $0.4 \mathrm{~g} / \mathrm{L}$ & $0.4 \mathrm{~g} / \mathrm{L}$ & - \\
3. & $\mathrm{CaCl}_{2}$ & $0.14 \mathrm{~g} / \mathrm{L}$ & $0.8 \mathrm{~g} / \mathrm{L}$ & - \\
4. & $\mathrm{NaHCO}_{3}$ & $0.35 \mathrm{~g} / \mathrm{L}$ & - & - \\
5. & $\mathrm{C}_{6} \mathrm{H}_{12} \mathrm{O}_{6}$ & $1 \mathrm{~g} / \mathrm{L}$ & - & - \\
6. & $\mathrm{MgSO}_{4} \times 7 \mathrm{H}_{2} \mathrm{O}$ & $0.2 \mathrm{~g} / \mathrm{L}$ & - & - \\
7. & $\mathrm{KH}_{2} \mathrm{PO}_{4} \times \mathrm{H}_{2} \mathrm{O}$ & $0.1 \mathrm{~g} / \mathrm{L}$ & - & - \\
8. & $\mathrm{Na}_{2} \mathrm{HPO}_{4} \times 7 \mathrm{H}_{2} \mathrm{O}$ & $0.06 \mathrm{~g} / \mathrm{L}$ & - & - \\
9. & $\mathrm{NaH}_{2} \mathrm{PO}_{4}$ & - & $0.79 \mathrm{~g} / \mathrm{L}$ & - \\
10. & $\mathrm{UREA}_{1 .}$ & - & $1 \mathrm{~g} / \mathrm{L}$ & $0.5 \mathrm{M}$ \\
1. & $\mathrm{C}_{6} \mathrm{H}_{8} \mathrm{O}_{7}$ & - & - & $\mathbf{1 . 8 1}$ \\
\hline $\mathbf{1 2 .}$ & $\mathbf{p H}$ & $\mathbf{7 . 2 5}$ & $\mathbf{4 . 8 0}$ & \\
\hline
\end{tabular}

For the investigation of corrosion processes the following electrochemical techniques were selected: open circuit potential (OCP), potentiodynamic polarization curves (PD), linear polarization resistance (Rp) and cyclic polarization (CV). The electrochemical measurements [16, 17] were performed at room temperature $\left(22 \pm 2^{\circ} \mathrm{C}\right)$ with a VoltaLab PGZ 100 and the data were recorded using the VoltaMaster4 software and each experiment was repeated at least three times to check the reproducibility. The open circuit potentials were monitored during the exposure time of $12 \mathrm{~h}$ until has been reached a stable state value vs. $\mathrm{Ag} / \mathrm{AgCl}$ reference electrode used. The polarization resistance, $\mathrm{R}_{\mathrm{p}}$, values were achieved by applying the linear polarization method around the free potential with a very low potential perturbation of $\pm 25 \mathrm{mV}$ around free potential to maintain the surface steady state with respect to the tested solution. The measurements started after one hour of immersion and after 24 hours from immersion, by measuring 30 linear polarization curves on each period. The applied scan rate of each polaization curve was $1 \mathrm{mV} / \mathrm{s}$. The Stern - Geary formula was applied to calculate each polarization resistance value and corrosion rate value. The potentiodynamic polarization (PD) 
diagrams were initiated from negative direction to positive direction from $-1500 \mathrm{mV}$ to $+1500 \mathrm{mV}$ vs. $\mathrm{Ag} / \mathrm{AgCl}$, with a scan rate of potential $1 \mathrm{mV} / \mathrm{s}$.

Cyclic polarization measurements $(\mathrm{CV})$ were performed at the same scan rate as the potentiodynamic polarization measurements from $-1500 \mathrm{mV}$ to $+2000 \mathrm{mV}$ and return to $-1500 \mathrm{mV}$.

\section{Chemical composition and SEM analysis of 304L stainless steel}

304L stainless steel was received in laminated sheets $(1000 \times 1000 \mathrm{~mm})$ of $1 \mathrm{~mm}$ thickness. It was cut into samples of the required dimensions for electrochemical corrosion tests $25 \times 25 \mathrm{~mm}$. After cutting into sample sizes, an electrical contact was made, and then a portion of them was insulated to accurately delimit the active surface area. The chemical composition and mechanical properties of 304L stainless steel are shown in Table 2.

Tabel 2. Chemical composition and mechanical properties of 304L stainless steel

\begin{tabular}{|c|c|c|c|c|c|c|c|c|c|}
\hline \multirow{2}{*}{ Stainless steel } & \multicolumn{9}{|c|}{ Chemical composition [ \% ] } \\
\hline & $\mathrm{Cr}$ & $\mathrm{Mn}$ & $\mathrm{Si}$ & $\mathrm{P}$ & $S$ & $\mathrm{Ni}$ & $\mathrm{Cu}$ & Mo & $\mathrm{Ti}$ \\
\hline $304 \mathrm{~L}$ & 19.79 & 1.74 & 0.17 & 0.028 & 0.005 & 10.02 & 0.86 & 0.74 & 0.15 \\
\hline \multicolumn{3}{|c|}{$\begin{array}{c}\text { Tensile Strength, Yield } \\
{[\mathrm{MPa}]}\end{array}$} & \multicolumn{3}{|c|}{$\begin{array}{c}\text { Tensile Strength } \\
{[\mathrm{MPa}]}\end{array}$} & & \multicolumn{3}{|c|}{$\begin{array}{c}\text { Elongation, A50 mm } \\
{[\%]}\end{array}$} \\
\hline \multicolumn{3}{|c|}{210} & \multicolumn{3}{|c|}{520} & & \multicolumn{3}{|c|}{45} \\
\hline
\end{tabular}

\section{Results and discussions}

\section{SEM surface micrograph of 304L stainless steel}

Figure 1(a) and (b) show the 304L surface morphology both on polished surface sample, Fig. 1(a) and on electrochemically etching surface sample, Figure 1(b). The chemical etching solution was prepared by mixing $5 \mathrm{~mL}$ concentrated nitric acid and $0.5 \mathrm{~mL}$ hydrofluoric acid with $100 \mathrm{~mL}$ alcohol ethylic.

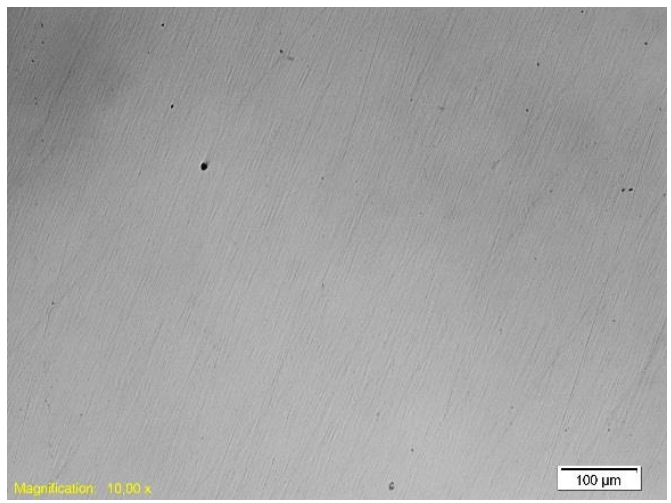

(a)

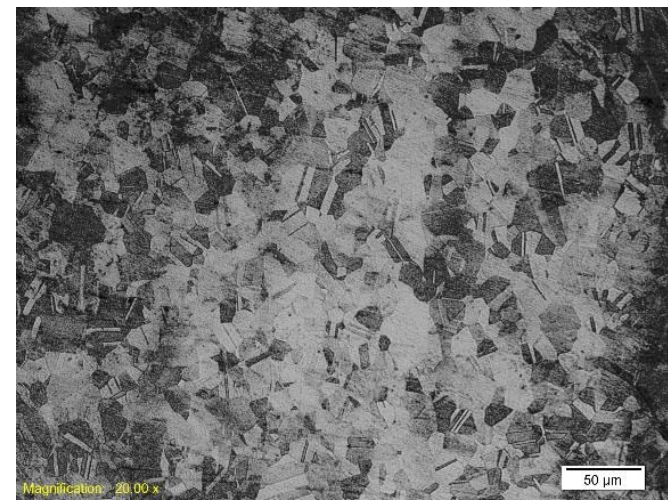

(b)

Figure 1. SEM surface micrograph of 304L stainless steel: (a) polished surface; (b) surface etched with mixture of nitric acid and hydrofluoric acid

\section{Evolution of open circuit potential during immersion time}

When an electronic conductor material is immersed in an electrolyte, an $\mathrm{E}$ or $\mathrm{U}$ potential difference occurs at the material-solution interface called electrode potential. It is not directly measurable; we can not measure the potential difference at the terminals of a cell formed by a complete electrochemical chain. If the electrode introduced to constitute the chain is well defined and 
stable over time, it is called a reference electrode, and it is then possible to compare different electrodes between them in relation to the adopted reference. Open circuit potential analysis evolution in time is useful information to track the behavior of a material in contact with a wet corrosive environment. The physical-chemical reactions present at the surface of the material modify the solidsolution interface, which explains the evolution of the potential. This analysis can be assured by means of an acquisition device potentiostat-galvanostat. Figure 2 shows the evolution of free potentials (OCP) of 304L stainless steel from immersion in the tested solutions monitored for $12 \mathrm{~h}$, respectively 720 $\min$.

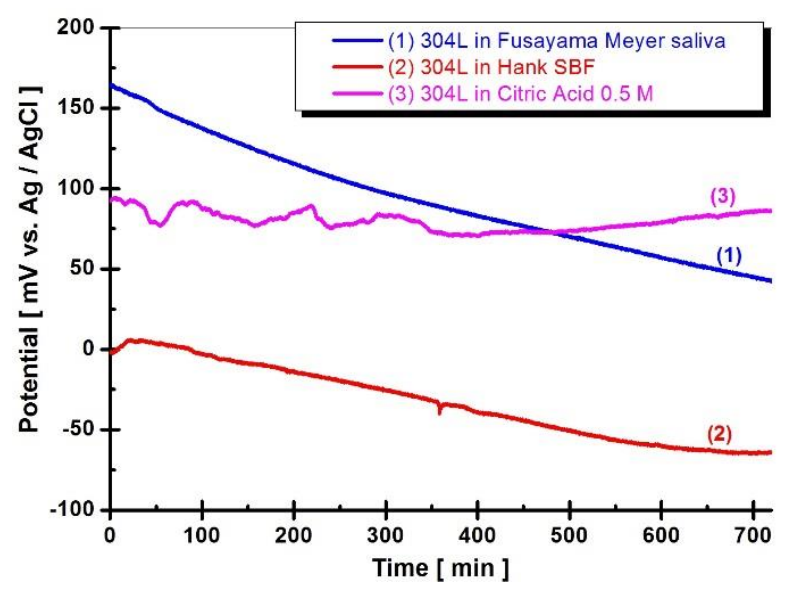

Figure 2. Open circuit potential evolution during immersion time of $12 \mathrm{~h}$

As it is known the stainless steels owe their good corrosion behavior to a chromium oxide passive layer formed instantaneously on the surface in the presence of oxygen. It is made up of a film of oxide having only a nanometer thickness and whose formation depends on the potential and the oxidative characteristics of the environment. Continuing the monitoring of the open circuit potential within 12 hours after immersion, a change in the tendency is observed from immersion time as can be seen in Figure 2. The citric acid potential stabilizes at a constant value. The potentials shown in the two biological solutions tend to move towards more negative, active values explained by the presence of chloride aggressive ions into solutions.

\section{Potentiodynamic polarization (PD)}

The $\mathrm{i}=\mathrm{f}(\mathrm{E})$ (current density versus potential) diagrams traced in a wide range of potential from cathodic potential to anodic potential with a constant scanning rate allow us to make some predictions on the material and the environment. It can be distinguished 4 domains: The cathodic domain, where the passive film is destroyed by releasing hydrogen. Critical or active and domain, where the passive film is formed but is competing with the dissolution of the metal or alloy; it is an area of instability. Passive domain, where the passive film is formed over a wide range of potentials. The breadth of this domain depends on the studied material and the corrosive environment. Transpassive domain, where dissolution through the passive film occurs with a deterioration of the alloy surface. The curves $i=f$ (E) for all tested solutions are shown in Figure 3. 


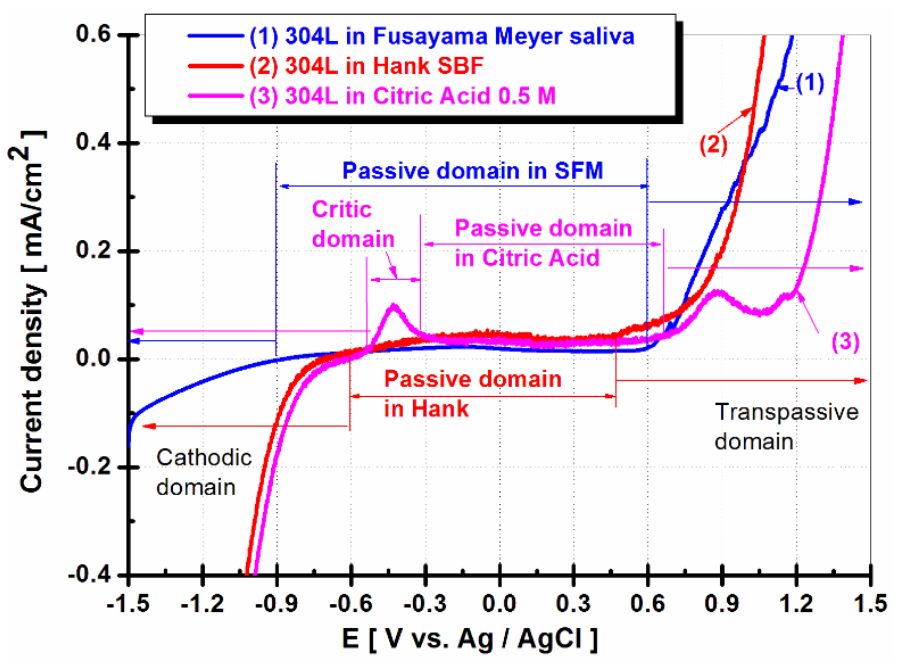

Figure 3. Potentiodynamic polarization diagrams of 304L stainless steel in different $p \mathrm{H}$ solutions with different compositions

The diagrams show the different potential domains, the current densities and the potentials corresponding to the states of "activity (or critical)", then "passive domain" or "passivity" (stable) followed by "transpassivity". The potential for passive state is different for the immersed 304L stainless steel in the three solutions. Thus the largest passive domain is obtained in the Fusayama Meyer saliva, ranging from $-0.9 \mathrm{~V}$ to $+0.6 \mathrm{~V}$ vs. $\mathrm{Ag} / \mathrm{AgCl}$ (curve 1, Figure 3). The narrowest passive domain is achieved in the Hank biological solution, ranging from $-0.6 \mathrm{~V}$ to +0.46 (curve 2 in Figure 3). For stainless steel immersed in citric acid it appears the active or critical domain where dissolution occurs before the passive state of the surface. is established. The critical domain range between -0.546 to $-0.313 \mathrm{~V}$ vs. $\mathrm{Ag} / \mathrm{AgCl}$ (curve 3 on Figure 3), followed by passive domain ranging from -0.313 to $+0.667 \mathrm{~V}$ (curve 3 on Figure 3). In the transpassive domain for all solutions, the passive film loses its protective properties and even disappears at higher potentials.

From the practical point of view, the relative width of each domain and the associated values depend directly on the material / medium system. The same material, 304L stainless steel, behaves differently in different $\mathrm{pH}$ solutions and different compositions tested, Figure 3.

Transpassivity may in some cases results from a destabilization of the environment; for example in an aqueous medium, may be the decomposition of oxygen-releasing water.

\section{Cyclic polarization measurements (CV)}

By comparison with the active and passive domains, the transpasive domain is not unique; it depends on the presence or absence of a superficial oxide film. If a potential localized corrosion occurs with the development of pitting corrosion, then the notion of pitting corrosion potential is introduced. These can be highlighted by cyclic polarization. The comparative cyclic polarization curves are shown in Figure 4 for the three solutions. Although Hank's solution has the most neutral potential (7.25), due to the presence of higher concentration of chlorides than Fusayama Meyer's saliva, the corrosion curve, diagram 2 from Figure 4 show the specific hysteresis due to localized corrosion etching (pitting).

The smallest current density is shown by 304L stainless steel immersed in Fusayama Meyer's saliva, while the highest current density is shown by 304L stainless steel immersed in Hank biological solution, proving that a higher corrosion process occurs on 304L stainless steel surface in Hank biological solution. On the surface of 304L stainless steel immersed in citric acid solution a general corrosion occurs, as it is shown in diagram 3 from Figure 4. No hysteresis aspect is revealed on this diagram. The passive film is not stable due to lower $\mathrm{pH}$ of the solution. 


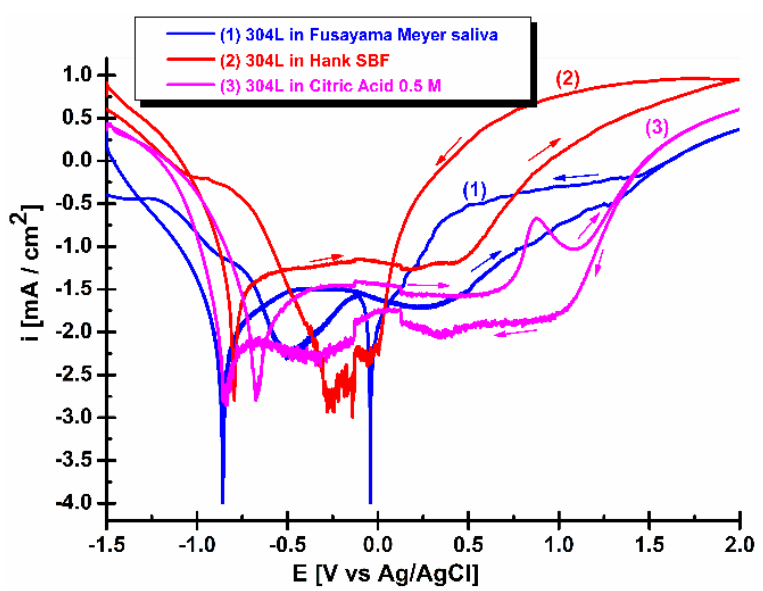

Figure 4. Cyclic polarization diagrams of 304L

Stainless steel in the three tested solutions

\section{Polarization resistance and corrosion rate measurements}

The polarization resistance, $\mathrm{Rp}$, values was achieved by the linear polarization method around the free potential with a very low potential perturbation of $\pm 25 \mathrm{mV}$ around free potential to maintain the surface steady state with respect to the tested solution. The measurements started after one hour of immersion and after $24 \mathrm{~h}$ from immersion, by measuring 30 linear polarization curves on each period. The results are shown in Figure 5(a) and (b) for polarization resistance and corrosion rate (as penetration rate), respectively, after one hour of immersion. In Figure 6(a) and (b) are shown the results obtained after $24 \mathrm{~h}$ from immersion. For simple corrosion systems, corrosion reactions are strictly controlled by mass transfer and corrosion current density, $\mathrm{i}_{\text {corr, }}$ can be correlated with polarization resistance, $\mathrm{R}_{\mathrm{p}}$, through the relationship:

$$
i_{\text {corr }}=\frac{B}{R_{p}} \quad \text { Stern - Geary Equation }
$$

The corrosion rate is expressed in this case in $\mathrm{A} / \mathrm{cm}^{2}$.

$\mathrm{B}$ is a constant specific to each system material - environment, given by the equation:

$$
B=\frac{b_{a}\left|b_{c}\right|}{2.303\left(b_{a}+b_{c}\right)}
$$

where $b_{a}$ and $b_{c}$ are the Tafel slopes anodic and cathodic respectively.

Increasing the polarization resistance means the decrease of the corrosion current density and thus the corrosion rate.

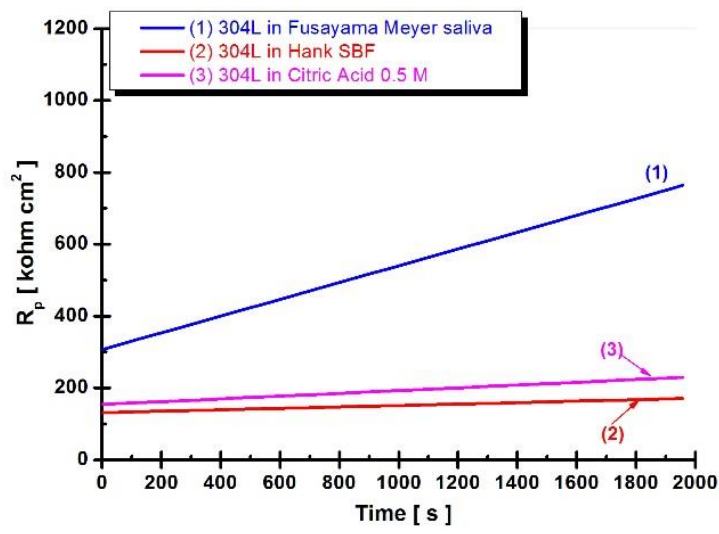

(a)

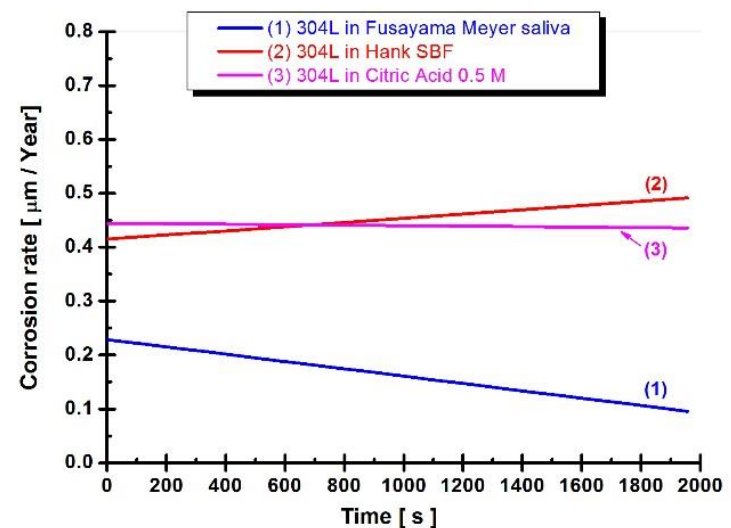

(b)

Figure 5. The evolution of polarization resistance (a) and corrosion rate (b) of 304L 
after $1 \mathrm{~h}$ of immersion

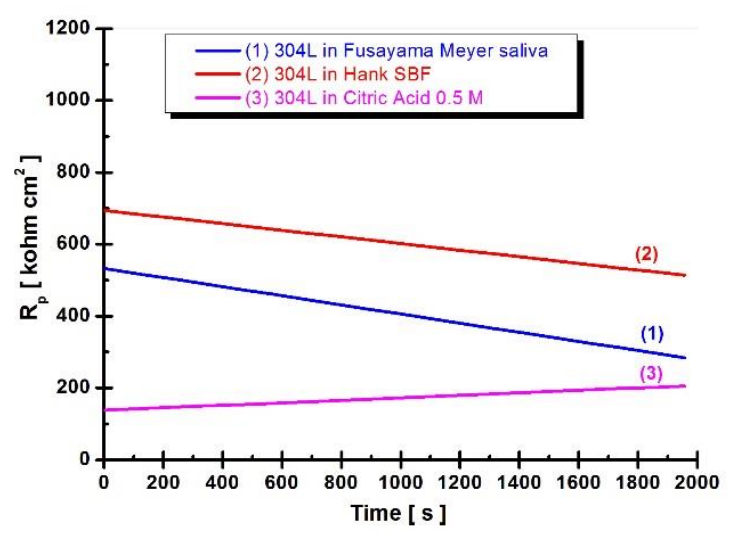

(a)

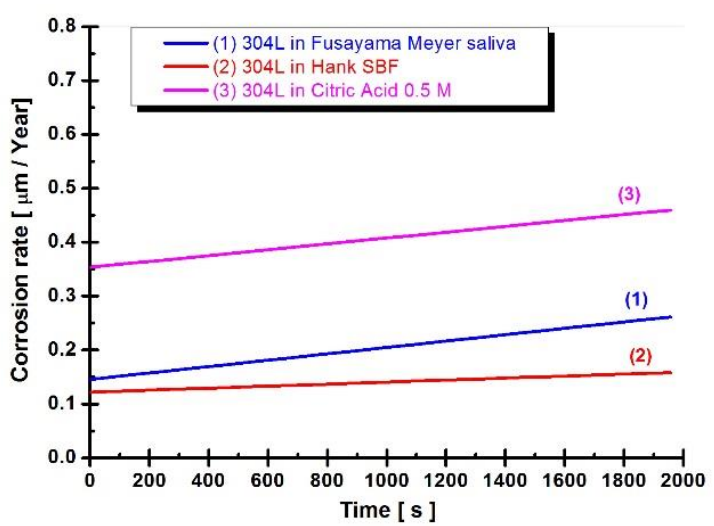

(b)

Figure 6. The evolution of polarization resistance (a) and corrosion rate (b) of 304L after $24 \mathrm{~h}$ of immersion

By analyzing the results it can be seen that after one hour of immersion the polarization resistance of 304L stainless steel immersed in Hank biological solutions, curve 2 from Figure 5(a) and citric acid solution, curve 3 from Figure 5(a) show similar values around $50 \mathrm{kohm} \cdot \mathrm{cm}^{2}$. The corrosion rates have also appropriate values for these two solutions, Figure 5(b). The polarization resistance of 304L stainless steel immersed in Fusayama Meyer biological solution is constantly increasing during the measurements after one hour, proving the formation of protective passive film, curve 1 from Figure $5(\mathrm{a})$, having higher value as compared with Hank solution. The corrosion rate is smaller from the first measurements and shows a constantly decreasing trend during measurements as compared with the Hank biological solution or citric acid solution.

After $24 \mathrm{~h}$ from immersion the polarization resistance of 304L stainless steel immersed in citric acid remains in the same range value with a slightly increasing trend during measurements, curve 3 from Figure 6(a). The corrosion rate of 304L stainless steel in this solution remains also constant with a slight tendency of decreasing values during measurements.

The polarization resistances of 304L stainless steel immersed in both biological solutions, SFM and Hank, after 24 hours from immersion, show higher values as compared with polarization resistance in citric acid solutions, curve 1 and curve 2 from Figure 6(a). Instead these values have a tendency to decrease during the measurements, proving great instability of $304 \mathrm{~L}$ stainless steel surface. The corrosion rate values of 304L stainless steel surface in SBF and Hank biological solution are lower as compared with those measured in citric acid solution after $24 \mathrm{~h}$ from immersion, but show a slightly increasing trend during measurements.

\section{Conclusions}

Corrosion of materials is a very important process to consider when choosing a material that needs to work in a specific environment.

304L stainless steel has shown a different behavior during corrosion tests by electrochemical methods in solutions with different $\mathrm{pH}$, different content of chlorides and different oxidizing character.

The potential values shown in the two biological solutions tend to move towards more negative, active values explained by the presence of chloride aggressive ions into solutions.

From the Potentiodynamic polarization diagrams it is concluded that 304L stainless steel show different active or passive state in the three tested solutions. The larger passive domain and lower passive current density is reached by immersion in citric acid solution.

304L stainless steel is very sensitive to pitting corrosion as it was revealed by cyclic polarization 
measurements in the Hank biological solution, observed on the cyclic polarization curves just after few hours of immersion.

The polarization resistance and corrosion resistance revealed also the higher instability of 304L stainless steel immersed in Hank and Fusayama Mayer biological solutions.

Electrochemical methods used for this study are pertinent methods for the study of a biomaterial / environmental interface, corrosion behavior being specific to the system as a whole.

Acknowledgements. All the research experimental work was performed in the laboratories of Competences Centre Interfaces - Tribocorrosion and Electrochemical Systems (CC-ITES), from Dunărea de Jos University of Galati. We thank UEFISCDI - Ministry of Education and Research for the financial support to Competences Centre Interfaces - Tribocorrosion and Electrochemical Systems (CC-ITES) - Dunarea de Jos University of Galati - Research Project: HyBioElect, contract 10 /30-082013 in the frame of National Research Programme Romania - PN II PCE.

\section{References}

1. ANDERSON, JM., RODRIGUEZ, A., CHANG, DT., Semin. Immunol., 20, 2008, p. 86.

2. MANIVASAGAM, G., DHINASEKARAN, D., RAJAMANICKAM, A., Recent Patents on Corrosion Science, 2, 2010, p. 40.

3. HENCH, LL., THOMPSON, I., J. R. Soc. Interface, 7, 2010, p. 379.

4. HEDBERG, Y., WALLINDER, IO., Biointerphases, 11, 2016, p. 018901.

5. IZQUIERDO, PP., BIASI, RS., ELIAS, CN., NOJIMA, LI., Am. J. Orthod. Dentofacial Orthop., 138, 2010, p. 714.e1.

6. BLACKWOOD, DJ., Reference Module in Materials Science and Materials Engineering, 2016, doi:10.1016/b978-0-12-803581-8.01614-3.

7. GOUTIER, F., VALETTE, S., LABORDE, E., LEFORT, P., J. Alloy. Compd., 509, 2011, p. 3246.

8. DAVOODI, A., PAKSHIR, M., BABAIEE, M., EBRAHIMI, GR., Corros. Sci., 53, 2011, p. 399.

9. REFAEY, SAM., TAHA, F., ABD El-MALAK, AM., Appl. Surf. Sci., 242, 2005, p. 114.

10. CHATURVEDI, TP., Indian J. Dent. Res., 25, 2014, p. 630.

11. SHARMA, MR., MAHATO, N., CHO, MH., CHATURVEDI, TP., SINGH, MM., Matter. Technol., 34, 2018, p. 1.

12. FAN, DM., ZHU, CF., XIA L., WANG, XJ., Corrosion and Protection, 34, 2013, p. 314.

13. MAHATO, N., SHARMA, MR., CHATURVEDI, TP., SINGH, MM., Mater. Lett., 65, 2011, p. 2241.

14. HEDBERG, Y., KARLSSON, ME., BLOMBER, E., WALLINDER, GIO., HEDBERG, J., Colloid Surface B, 122, 2014, P. 216.

15. SIMIONESCU, N., RAVOIU, A., BENEA, L., Rev. Chim., 70, (4), 2019, 1144.

16.*** "Standard Practice for Conventions Applicable to Electrochemical Measurements in Corrosion Testing," G3-14, ASTM International, West Conshohocken, PA, 2014, DOI: 10.1520/G0003-14.

17.***"Standard Test Method for Conducting Potentiodynamic Polarization Resistance Measurements," G59-97, ASTM International, West Conshohocken, PA, 2014, DOI: 10.1520/G005997R14.

Manuscript received: 3.02 .2020 